\title{
Gross Anatomical Studies of the Bones of the Tho- racic Limbs of the Lion (Panthera leo)
}

\author{
Nzalak, J.O; Eki, M.M; *Sulaiman, M.H; Umosen, A.D; Sa- \\ lami, S. O., Maidawa, S.M and Ibe, C.S
}

Department of Veterinary Anatomy, Ahmadu Bello University, Zaria, Nigeria

Received August, accepted for publication October 2010

\section{Abstract}

This work was conducted with the aim of studying the gross anatomical features of the bones of the thoracic limb of the lion (Panthera leo). Consequently, gross anatomical study was carried out on the already prepared bones of the thoracic limbs namely; the scapula, humerus, radius, ulna, carpus, metacarpus and the digits.

\section{Keywords}

Lion (Panthera leo), Bones, Gross anatomy, Thoracic limb

\section{Introduction}

Felidae is the generic name of the cats; a member of this cat family is called felid or feline. Felids are the strictly carnivores of the mammalian family the order Carnivora. The most familiar felid is the domestic cat, which first became associated with humans about 10,000 years ago, but the family includes all other

wild cats including the big cats (Nowak, 1999).

The lion (Panthera leo) is one of four big cats in the genus Panthera, and a member of the family Felidae. With some males exceeding $250 \mathrm{~kg}$ (550 lb) in weight (Nowak, 1999), it is the second-largest living cat, after the tiger. Wild lions currently exist in Sub-Saharan Africa and Asia, with a critically endangered remnant population in northwest India, having disappeared from North Africa, the Middle East, and western Asia in historic times. Until the late Pleistocene, which was about 10,000 years ago, the lion was the most widespread large land mammal after humans. They were found in most of Africa, Euro-Asia from Western Europe to India, and in the Americas from the Yukon to Peru.

Lions live for 10-14 years in the wild, while in captivity they can live over 20 years. In the wild, males seldom live longer than 10 years, as fights with rivals occasionally cause injuries (Smuts, 1982). The lion is an apex and keystone predator, although they will scavenge if the 
situation dictates so. While lions do not typically hunt humans selectively, some have been known to become man-eaters and seek human prey. The lion is a vulnerable species, having seen a possibly irreversible population decline of 30 to $50 \%$ over the past two decades in its African range (Nowell and Bauer, 2004).

The aim of this study was to elucidate the gross anatomical features of the thoracic limbs of the lion. To our knowledge, there are no literature on the detailed gross anatomical features of the thoracic limbs of the lion, especially in Nigeria and the Sub Saharan Africa.

\section{Materials and Methods}

\section{Extraction of the bones from the embalmed lion}

The carcass of a dead lion was utilized for this study, in the Department of Veterinary Anatomy, Ahmadu Bello University Zaria, Nigeria. The limbs were detached and were soaked in hot $10 \%$ Potassium Hydroxidefor 5 days. This was to clear the muscles and other soft tissues. Subsequently, the bones were air-dried in the open Sub-Saharan sun for a week. Photographs of the thoracic limbs were taken using Sony 10.1 mega pixels digital camera.

\section{Results}

\section{Scapula}

The scapula was triangular in shape with 2 surfaces, 3 borders and 3 angles; the lateral surface was divided into 2 unequal fossae by a well-developed scapular spine. The acromion process, overhanging the glenoid notch, was composed of a hamate process and a suprahamate process. The meta-acromium process was well-developed and curved caudally. The sub scapular fossa was very deep, near the glenoid cavity. The cranial border was convex and circular in outline, whereas the caudal border was straight. The cranial angle was not well-distinct and it merged with the adjacent borders, whereas the caudal angle was thick, rough and tuberous.

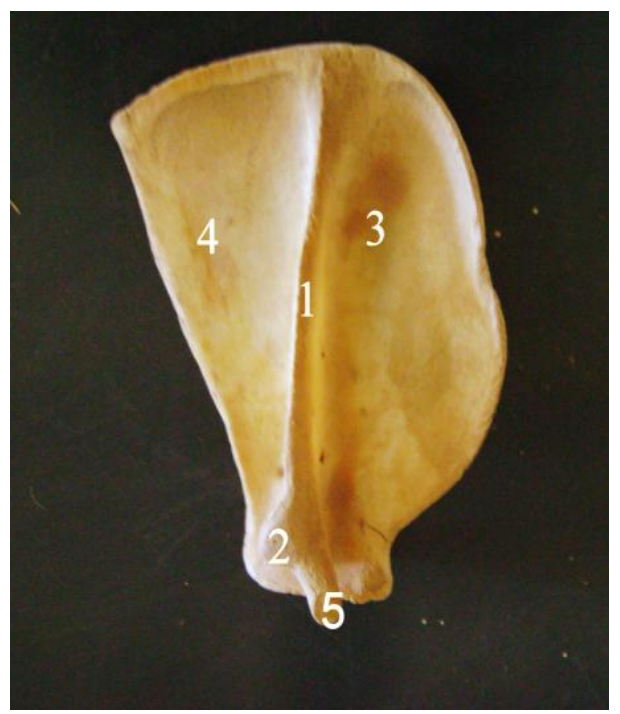

Fig (1): Lateral surface of the left scapula. 1 scapular spine, 2hamate process, 3 supraspinous fossa, 4 infraspinous fossa, 5 suprahamate process. 


\section{Humerus}

The Humerus of the lion was a long bone with a spirallytwisted shaft. The body of the humerus was somewhat compressed laterally. The humeral head was long and strongly curved cranio-caudally; the neck was distinctly marked, while the distal end had condyles and epicondyles. The medial condyle was larger than the lateral one. The nutrient foramen of the diaphysis was located on the caudal surface of the distal half of the humerus.

\section{Radius}

The radius was cranio-lateral to the ulna at the cubital articulation, and cranio-medial to the ulna at the carpal articulation. The rough caudal surface of the radius was the border facing the ulna; this interosseous surface had a nutrient foramen near the proximal end of the radius. The concave fovea capitis radii of the head of the radius articulated with the lateral condyle of the humerus. The radial tuberosity was a small eminence on the medial surface of the radius, near the transverse level of the ulnar tuberosity (Fig.3).The radius has an elongated medial projection at its distal end which is the medial styloid process.

\section{Ulna}

The ulna was the longest bone of the forearm of the lion. It extended from point of the elbow to the carpus. As seen in figure 4, there was a large trochlear notch present at theproximal cranial surface of the ulna which articulated with the humeral trochlea. The two projections that associate to form the proximal and distal margins of the trochlear notch were the anconeal and coronoid processes respectively. The distal extremity is represented by the styloid process.

\section{Carpus and Metacarpus}

Figure 5 shows some of the carpal and metacarpal bones. The lion had seven carpal bones that were arranged in two rows; a proximal row of three bones (intermedoradial,ulnar, accessory), and a distal row of four bones (I-IV).

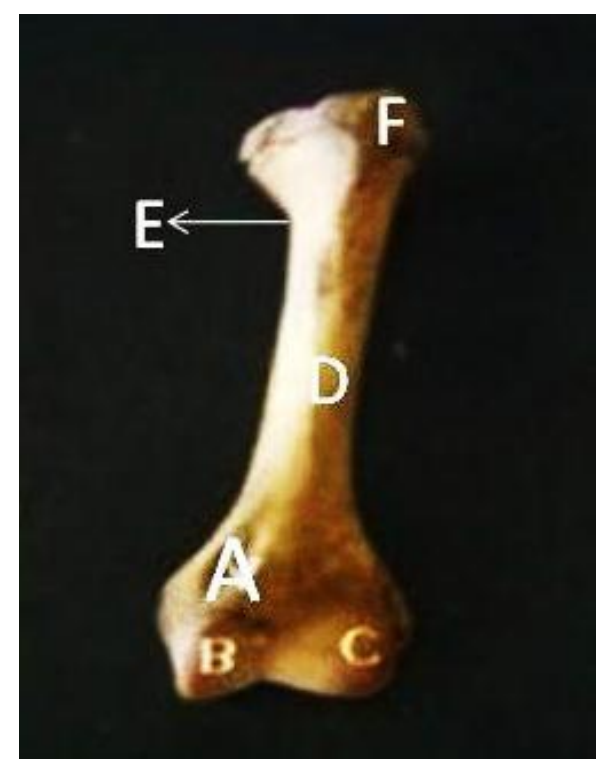

Fig (2): Caudal surface of the left humerus. A supracondylar foramen, B lateral condyle, C medial condyle, D Humeral shaft, E Humeral neck, F Humeral head. 
The metacarpus was distal to the carpus and proximal to the digits, it was made of five metacarpal bones (Metacarpal I-V). Each metacarpal bone had a proximal base, a body and a distal end (head). The Metacarpal I was the smallest of the metacarpal bones.

\section{Digits}

In this study, we observed that digits II, III, IV, and V had 3 phalanges each while digit I had only 2 . The proximal phalanx of digit I and the proximal and middle phalanges of digits II, III, IV, and V had a proximal base, a body, and a distal head. The distal phalanx of digits I-V had a dorsal prominence, the extensor process; a palmar flexor tubercle; a distal crest of the claw; and a process of the claw. The crest of the distal phalanx projected distally and superficially to the dorsal and lateral proximal surfaces of the cutaneous claw. The base of the crest of the distal phalanx was the extensor process. A pair of elastic ligaments attached the crest of the distal phalanx to the middle phalanx, resulting in overextension of the distal interphalangeal joint. The process of the claw was the bony extension of the distal phalanx into the cutaneous claw.

\section{Discussion}

The scapula of the lion possesses an osseous clavicle, and the acromion is composed of hamate and suprahamate processes. The suprahamate process is a caudally

J. Vet. Anat.

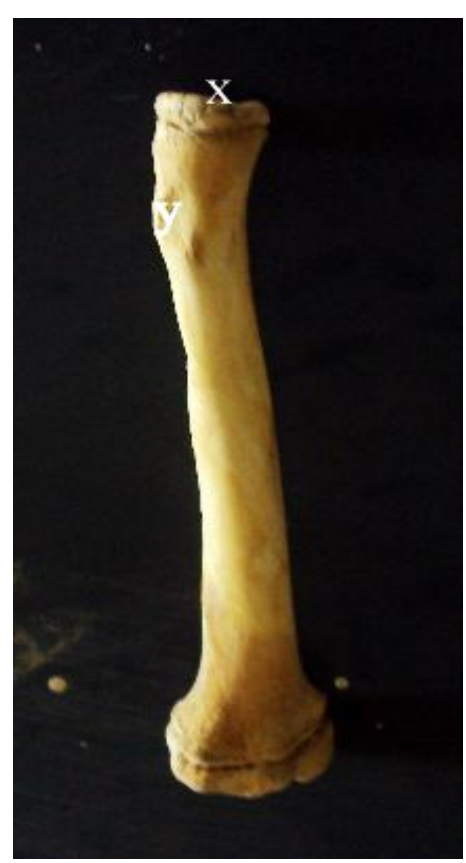

Fig(3):Caudal surface of the left radius. $x$ fovea capitis, $y$ radial tuberosity.

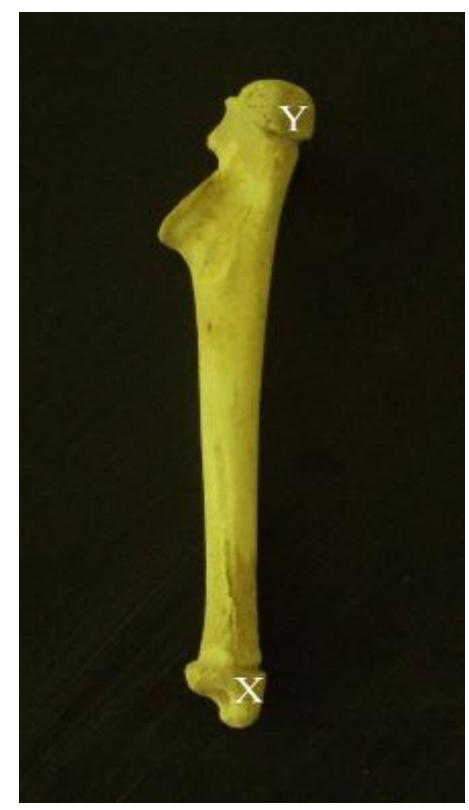

Fig(4):Medial surface of the left ulna. Xmedial styloid process, $\mathrm{Y}$ Olecranon tuberosity. 


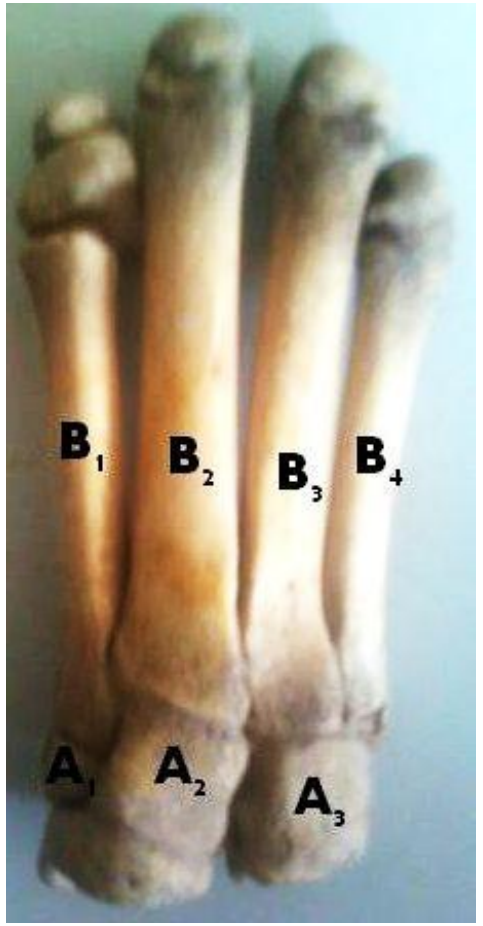

Fig (5):Carpal and metacarpal bones $\left(A_{1}-A_{3}=\right.$ carpal bones, $B_{1}-B_{4}=$ metacarpal bones)

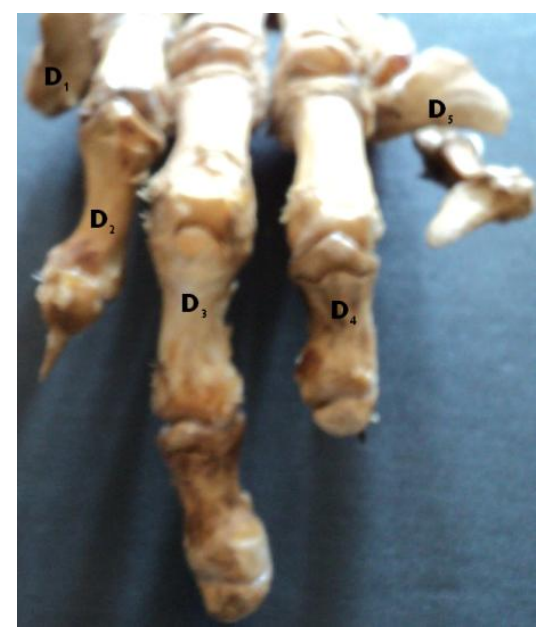

Fig (6): Digits of the lion. $D_{1}$ Digit $I, D_{2}$ Digit II, $\mathrm{D}_{3}$ Digit III, $\mathrm{D}_{4}$ Digit IV, $\mathrm{D}_{5}$ Digit V.

J. Vet. Anat. projecting prominence near the distal end of the scapular spine; the hamate process is a distal extension of the acromion that reaches the level of the humeral articulation, this is consistent with the report of Panday et al (2009) The tuber spine is absent on the scapular spine, but is present in the horse, pig, sheep and dog; in the cow it is present but not distinct (Sisson and Grossman, 1975). The spine is the most prominent feature on the lateral surface of the scapula of the dog (Miller, 1964).

The supracondylar foramen observed in the distal medial portion of the humerus together with an osseous passageway for the median nerve and brachial artery is unique only to the lion. In the horse the shaft is irregularly cylindrical and has a twisted appearance (Bradley, 1946). Conversely, in the cow the humerus has a shallow musculospiral groove and the deltoid tuberosity is less prominent than in the horse (Frandson,1972). Similarly, in the pig the musculo-spiral groove is also shallow, the medial surface is extensive and flattened; it is separated from the cranial surface by a distinct border and bears no teres tubercle (Frandson,1972).

The radius has an elongated medial projection at its distal end which is the medial styloid process and this has not been reported to the best of our knowledge in cattle, horse, pig and sheep. The styloid process has been reported in the dog (Miller, 1964). Also in the lion the rough caudal surface of the radius is the 
border facing the ulna; this interosseous surface has a nutrient foramen near the proximal end of the radius while in the horse the nutrient foramen is in the lower part of the groove (Walker, 1967). In the pig the radius is short and narrow but it is thick.

There are seven carpal bones arranged in two rows. The proximal row has three, the intermedioradial, ulna and accessory carpal bones. The distal row has four carpal bones numbered I, II, III, IV. The numerical reduction in the proximal row is apparently due to the fusion of the radial and intermediate, constituting a large bone, the intermedioradial, which articulates with almost the entire distal surface of the radius and with the bones of the distal row. This is in agreement with earlier studies (Hyman, 1942). Similarly, in the dog, the carpal bones are arranged in a proximal and distal rows such that there are three (radial, ulnar and accessory carpal bones) in the proximal and 4 (first, second, third and fourth carpal bones) in the distal row (Miller, 1964). Conversely, in the horse and pig, there are eight bones arranged in two rows, four proximally and distally (Sisson and Grossman, 1975). Similarly in the cow six carpal bones are present which are arranged as four proximally and two distally (Sisson and Grossman, 1975).

Five metacarpal bones have been observed in this study to be present in the lion, arranged from the medial to the lateral. The third and fourth are longer than the other three. The bodies of the bones are cylindrical in shape and have convex dorsal surface and concave palmar surface. While in the horse and pig three and four metacarpal bones respectively.

Each of the five digits has a proximal phalanx which is convex dorsally and concave palmary. We observed that the first digit has no middle phalanx and the middle phalanges have a median ridged articular surface. However, in the pigs four digits have been reported, and the bones resemble those of the cow in terms of form, while in the cow four digits are present, third and fourth are fully developed(Leach, 1961) while second and fifth are reduced; but in the horse one digit is present(Sisson and Grossman, 1975)

\section{References}

Bradley, O.C. (1946): The topographical anatomy of the limbs of the horse. Edinburgh W. Green and sons Ltd. Pp 230 - 241

Frandson, R.D. (1972): Anatomy and physiology of farm animals. Lea and Febiger Philadelphia. Pp 64, 81, 96.

Hyman, L.H. (1942): Comparative Anatomy. 2nd ed. University of Chicago press, Chicago. Pp 42- 47.

Leach, W.J. (1961): Functional 
Anatomy; $3^{\text {rd }}$ ed. New York McGraw Hill Book Co. Inc.

McClure, R. (1973): Cat Anatomy; An atlas,text, dissection guide. W.B. Saunders Co. Philadelphia. Pp. $18-26$.

Miller, M. E. (1964). The Anatomy of the Dog. W.B. Saunders Co. Philadelphia, pp. 64-78.

Nowak, R. M. (1999): Walkers mammals of the world. Baltimore John Hopkins universitypress. Pp 74, 92.

Nowell and Bauer(2004): Panthera leo IUCN Red List of threatened species. www.iucnredlist.org. pp 186.

Panday, S.P., Bhayani, D.M. and Vyas, Y.L. (2009): Indian Journal of Veterinary Anatomy.Indian Association of Veterinary Anatomists. Anand Agricultural University, Anand 388- 001 india
Sisson, S. and Grossman, J. D.

(1975): The Anatomy of the Domestic Animals, Fifth Edition, Vol, 1 \&2. Pp 8890,177 .

Smuts, G. L. (1982): Lion Johan nesburg: Macmillian South Africa publishers Pty Ltd. Pp 231

Walker W.F (1967): A study of the Cat. W.B.Saunders Co. Philadelphia. Pp 114- 116. 